Lithostratigraphy and study of

\section{planktonic foraminifera of the \\ Abderaz Formation at type \\ section, Kopet-Dagh basin, IRAN}

Meysam Shafiee Ardestani ${ }^{\text {* }}$, Mohsen allameh ${ }^{2}$,

Esmail Kohansal ${ }^{3}$

1- Department of Geology, Faculty of Science, Ferdowsi University of Mashhad, Mashhad, Iran

2- Department of Geology, Faculty of Science, Islamic azad University of Mashhad branch, Mashhad, Iran

3- Department of Geology, Faculty of Science, University of Tehran, Tehran, Iran

* Corresponding author:

m_shafiee@khayam.ut.ac.ir

\section{Abstract}

In order to study the fossil contents of the Abderaz Formation for biostratigraphical purposes the $\mathbf{3 0 0}$ meters thick section was sampled at type section. The sequence is mainly made up of grey shales and marls with two units of chalky limestone in upper part. The lower contact of the formation with Aitamir Formation is disconform while the upper contact with Abtalkh is continuous. There are huge amounts of inoceramids and ammonite. In the chalk limestone bonds of this formation which is belong to Santonian time planktonic, would exist some foraminifera with a less diversity because during the Santonian, the members of morphotype group three (M3) shows a regression in the abovementioned section, with association of tegilla shapes decreases in the area and sea water. The study of the planktonic foraminifera in isolated form led to differentiate three morphotype groups. The first group is characterized by trochospiral tests usually indicate shallow waters, the second group contains forms with strong ornamentations and the primary keels representing mid waters and finally compact trochospiral tests with keels known as deep water indices are included in the third group. Studies on the morphotypes showed a regressive cycle for Abderaz Formation.

Keywords: Abderaz Formation, Morphotype, Lithostratigraphy, Planktonic Foraminifera, Santonian 


\section{Introduction}

The Kopet-Dagh sedimentary basin had formed after the Middle Triassic orogeny in north-east Iran. The Kopet-Dagh Basin is located in northeastern Iran and southern Turkmenistan. It started sinking along major faults aligned approximately NW-SE. four of these major active basement faults have been recognized in the centre and western part of the basin. The blocks to the north of these basement faults subsided more rapidly than those which are on the southern side (Afshar-Harab, 1979; Berberian \& King, 1981). All the formations thin from the north-west to the south-east (Fig1). They were folded during the Late Alpine Orogeny and formed the structural traps of the Khangiran and Gonbadli gas fields. Composed mainly of sandstones, conglomerates, mudstones, limestones and dolomites with minor amounts of evaporite. The thickness of these sediments is normally more than $4000 \mathrm{~m}$, but only about $2500 \mathrm{~m}$ is in the eastern part of the basin. Mohajer (1976) and Afshar-Harb (1979) believed that the reduction in sediment thickness confirms that the Sarakhs area was more stable than other areas in the basin. And The Abderaz Formation is one of the upper cretaceous rock units in the Kopet-Dagh sedimentary basin in northeastern of Iran.

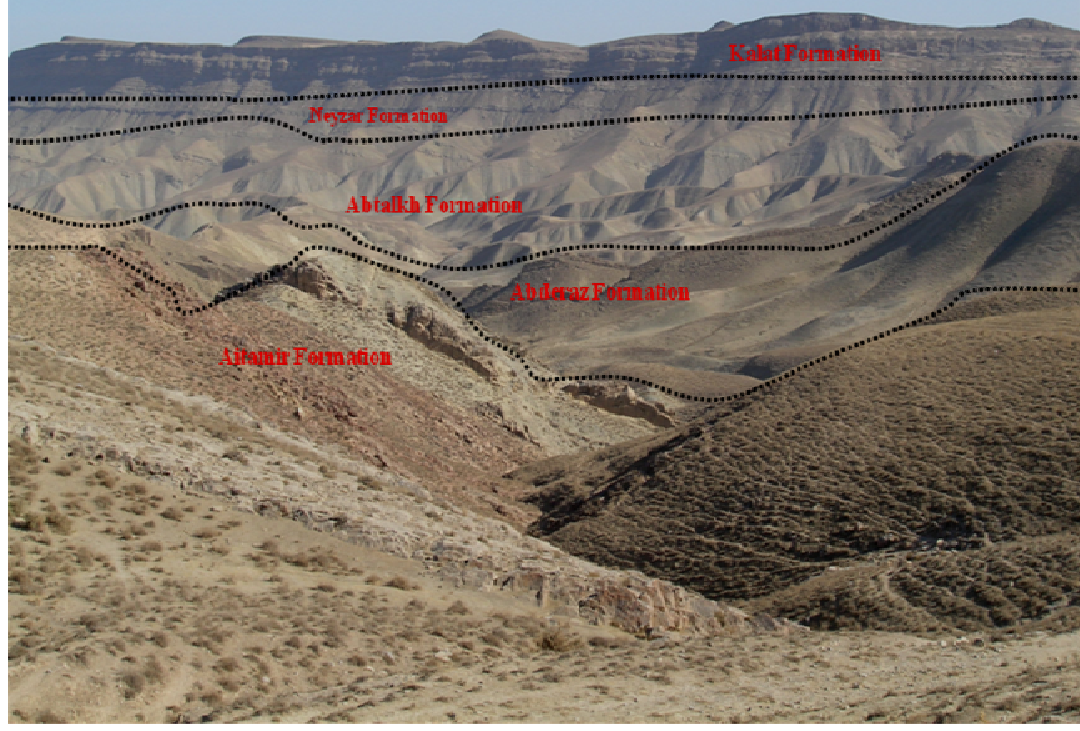

Fig1: Face of study area

\section{Aims of this study}

The systematic study of lithostratigraphy and morphotypes and planktonic to benthic ratio of the Abderaz Formation in KopetDagh basin, northeastern, Iran was the major aim of this research. This study was intended to explore the marine sedimentation of Abderaz Formation in (400meter) restrict . Then 168 SEM images have been obtained and demonstrated in frame of 1 plate.

\section{Lithostratigraphy}

Type section of Abderaz Formation has $300 \mathrm{~m}$ thickness (E: 60, 033', 00', N: 36 ${ }^{\circ}, 10^{\prime}$, 40/) NE Mashhad, placed in Mashhadsarakhs road far about $1 \mathrm{~km}$ to the Muzduran. At the typical gap such as all regions under the surface sub-contact of Abderaz Formation are un-correlated with 
Aitamir Formation. But its upper layer with Abtalkh Formation is in continuous correlation. The upper layer has elected as chalk limestone upper border. The subborder of the formation is the common border of silvery shale with olive shale of Aitamir Formation. (Fig.2)

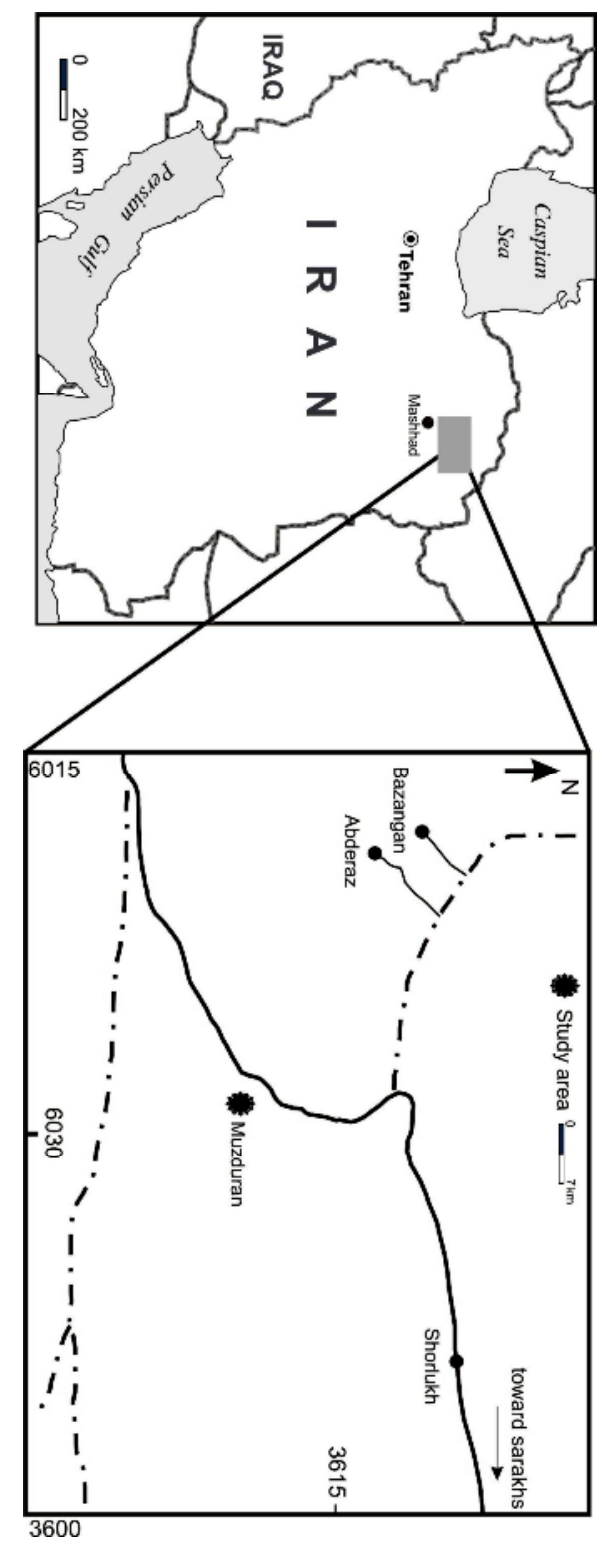

3- Thin bedded, grey to yellowish marl

4- Thin bedded, light green marl

5- Thin bedded, dark grey shales

6- Medium bedded, bluish limestone

7- Thin bedded, light grey marl

8- Yellowish chalk limestone

9- Light grey marl

10- Light grey shales

11- Medium bedded, White chalk limestone

Fig2: The geographical map and the ways to the region of the study 


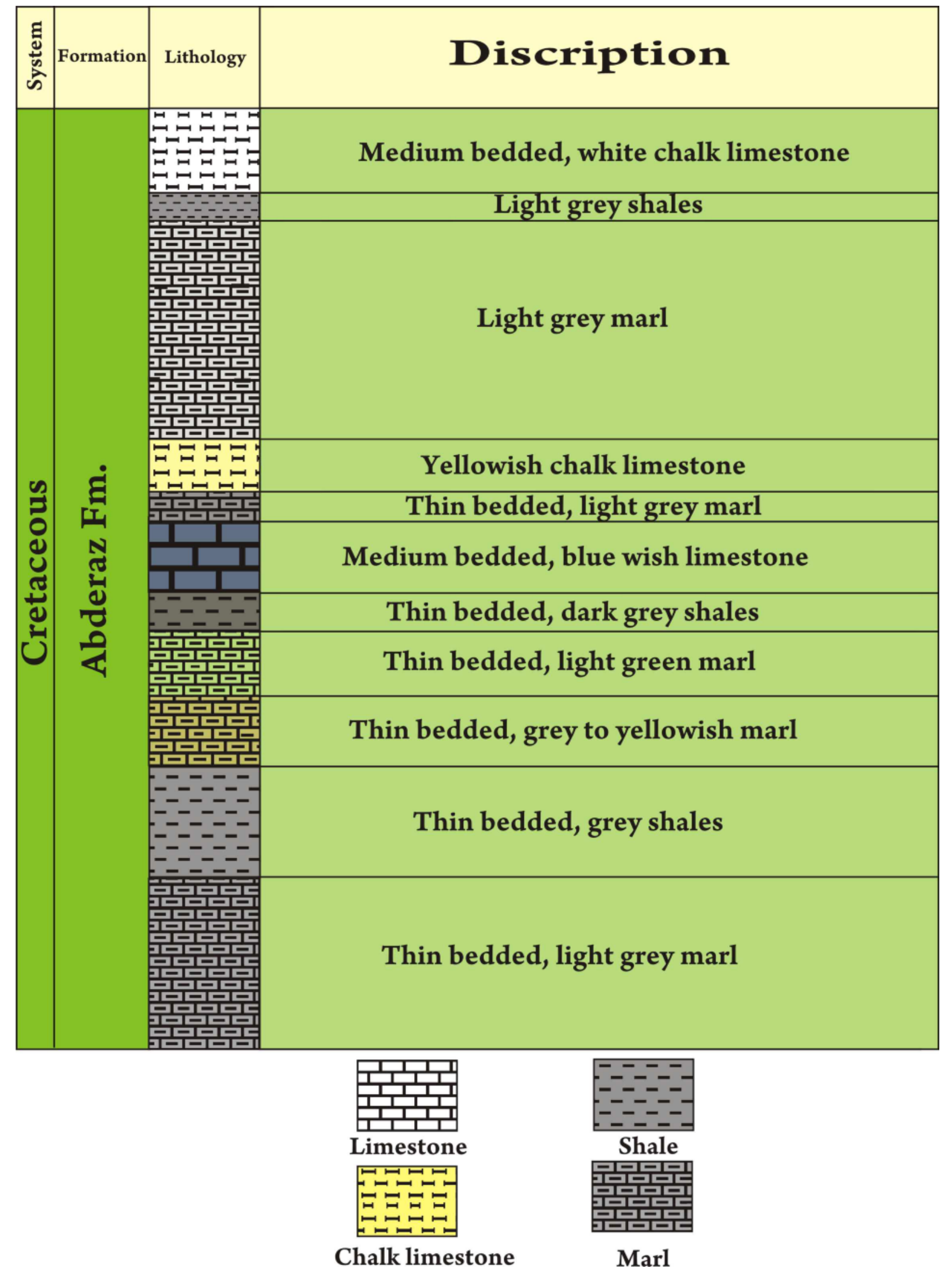

Fig3: lithostrtigraphic column in Abderaz Formation at type section 
At the type section is disconform like other regions the lower contact of the formation with Aitamir Formation. But the upper contact with Abtalkh Formation is continuous (Fig4).
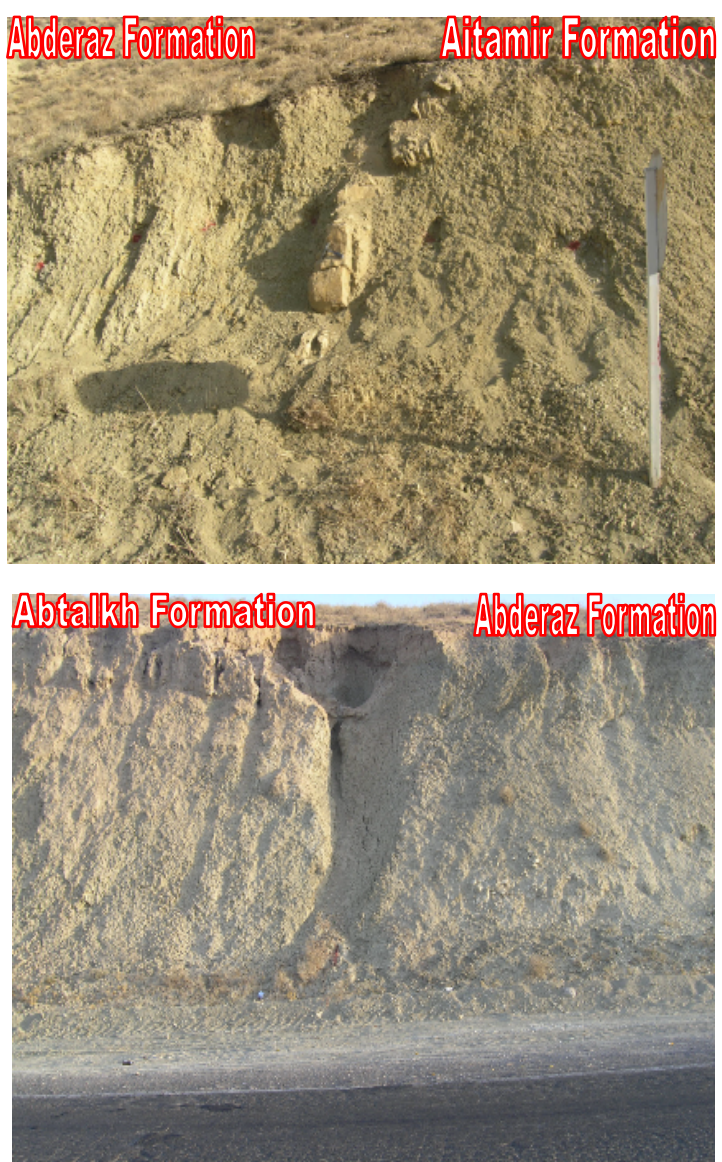

Fig4: Display of upper and lower contact of Abderaz Formation at type section

\section{Method}

One hundred thirty samples were gathered from the typical gap of Abderaz Formation in systematic with $300 \mathrm{~m}$ thickness. Only 102 samples were included in the studies, 7 samples due to the existence of salvation effects and 21 samples resulting from reworking damages were excluded from the study. Depending on the kind of lithology the samples were subjected for washing employing two methods (Shafieeardestani et al, 2008):

\section{1- Shale and marls samples:}

These samples were grid fully and included in the $\mathrm{H}_{2} \mathrm{O}_{2} \quad 10 \%$ daily, then with washing by water on the screeners assigned with meshes 125 and $63 \mu \mathrm{m}$.

\section{2- Chalk limestone samples:}

In this case the samples were also grid and the boiled in the $\mathrm{Na}_{2} \mathrm{SO}_{4}$ solution and then washed with water on the screeners assigned with the above mentioned meshes.

\section{Discussion}

The type section of the Abderaz Formation with a thickness of $300 \mathrm{~m}$ is located on the Mashad-Sarakhs road, some $90 \mathrm{~km}$ to the east of mashad and contains 11 lithological units mainly made of light grey shales bearing inoceramus and ammonites. The type section like other regions, the lower contact of the formation is disconform with Aitamir Formation. But the upper which contacts with Abtalkh Formation is continuous. The planktonic foraminifera with less diversity exist in the chalk limestone bonds of Abderaz formation benthic 
foraminifera with a lot of frequency. the chalk limestone is the members of morphotype group three (M3) with association of tegilla shapes and bonds in this formation which belongs to Santonian ,shows a regression in the above-mentioned section during Santonian and would decrease in the area and sea water. Base on this data we can recognize that by increasing the depth of lip structure it changes to a tegilla plate during million years that is an unstable structure with one edge. by the continues of this trend the orifice will fine a completely umbilical situation in the end of its evolution that all the mentioned trend leads to decreasing the surface to volume ratio in foraminifers shell that according to Pascal law it can have a great ability in living longer in much depths compare to their ancestors by the above- mentioned alters.

Groups of planktonic morphotyes are distinguished by depth of living (Hart, 1980a, Hart, 1980b, Wonders 1980, Keller, 1999) (Fig5). Those are consisting of:

\section{1- Shallow area faunas}

Heterohelix and Hedbergella and a big part of Hedbergella small samples like Globotruncanids genus are related to faunas of shallow epicontinental seas or the border sea (Eicher, 1969, Eicher and Worstell, 1970, Sliter 1972).

\section{2- Middle water faunas}

Praeglobotruncana and Whiteinella are related to this fauna.

3- Deep water faunas (lower than 100)

These faunas were counted like keeled shapes

there were $\mathbf{3 0 0}$ samples in the size of $\mathbf{1 2 0}$ mesh completely by chance, from every samples were counted that the result of this count shows at the first of successions and the time middle Turonian morphotype group one was conquering and the amount of the morphotype group 3 and \%P was les in the area that this paragraph. in the late Turonian the group of morphotype three was increasing in the area that it indicated the proportional increasing of depth in the area and by this time portici structure has been larger and in umbilical structure is born in this unicellular, and in Coniacian time has decreased the amount of morphotype three in the area again and the members of morphotype group one increased with the less $\% \mathrm{P}$ in the area again and during Coniacian to Santonian the members of morphotype group 3(M3) with \%Pincrease in the area for another time and in Santonian time, sea water shows a vacillation mood in the above-mentioned section. Also the planktonic to benthic ratio which explains that at the deposits $\mathbf{4 0 0}$ meter at total part of in this Formation. This study was intended to explore the marine sedimentation of 
Abderaz Formation in (outer neritic-upper bathyal) restrict and the provided curves from morphotypes changes are in full agreement with the curves of the sea level changes and planktonic foraminifer to epifauna benthic ratio(Fig5).

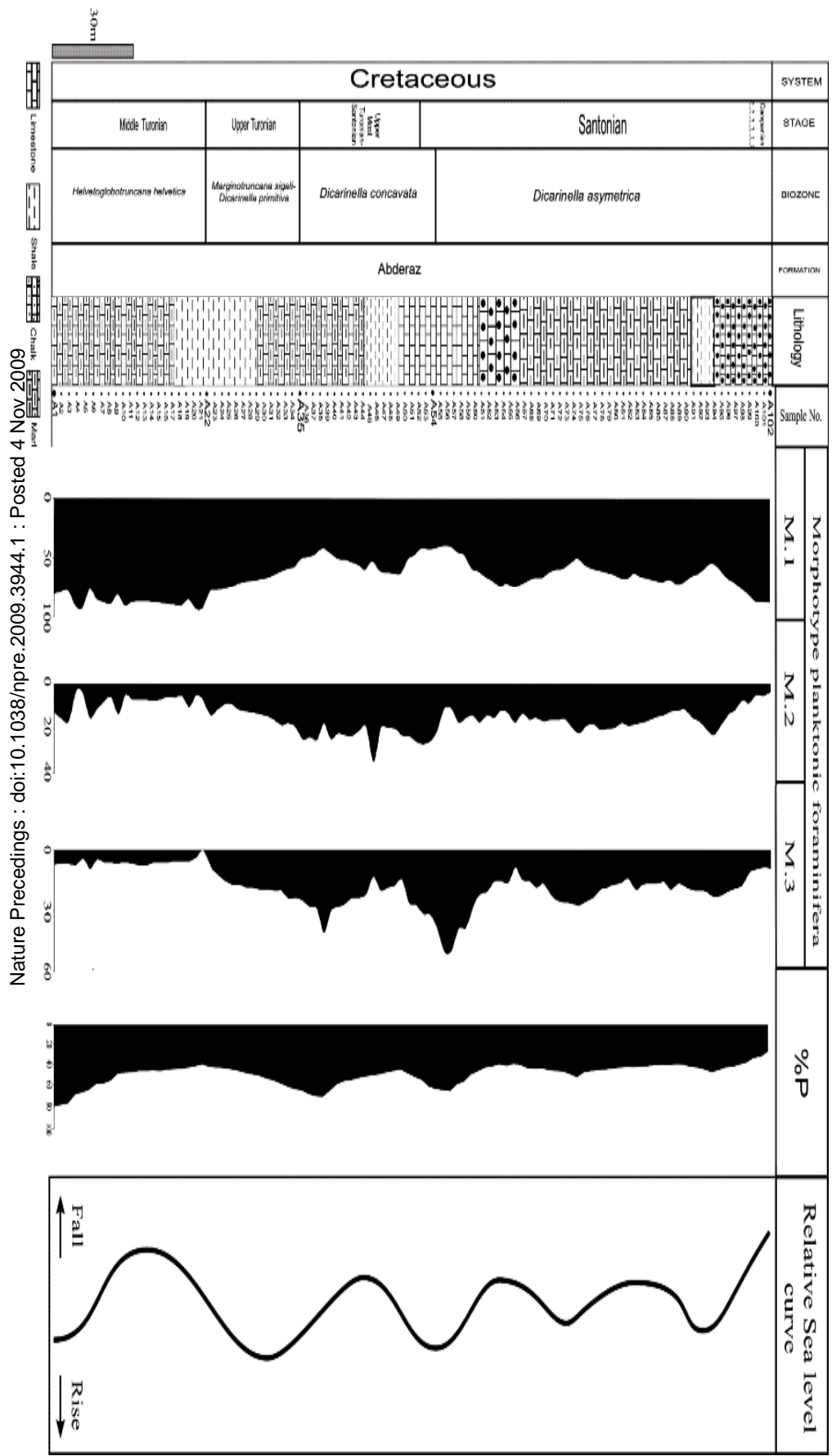

Fig5-Comparison of planktonic morphotype curves with \% ) $M 1=$ Morphotype group1, M2= Morphotype group2, M3= Morphotype group3, \%P=percentage of planktonic foraminifera)

\section{Result}

Groups of planktonic morphotyes are distinguished by depth of living that is consisting of:

\section{1- Shallow area faunas}

\section{2- Middle water faunas}

3- Deep water faunas (lower than 100)

in the time of middle Turonian simultaneous with subtraction of the percent of morphotype group three that indicates the dwindling of proportional in mentioned section. \%Pincreases but in the late Turonian that the percent of morphotype three increases that it would indicated the propotional of depth increasing in area and the structured shapes in vicinity has increased and the structured shaped (tegilla) recently has born and in Coniacian time the morphotype group three diminished again and \%Pincrease and in Coniacian -Santonian boundary by increasing the shapes of morphotype three and \%Pbecame the most in this time. that this affair it is because of the advent of Globotrancana and increasing the number of them in Santonian time but in the late Santonian and the early Campanian by diminishing the percent of morphotype three and increasing morphotype one , the lip shapes became more in area. This study was intended to explore the marine sedimentation of Abderaz Formation in 
(outer neritic-upper bathyal) restrict and the provided curves from morphotypes changes are in full agreement with the curves of the sea level changes and planktonic foraminifer to epifauna benthic ratio.

\section{Acknowledgments}

This project was financially supported by the vice chancellor for research at the Ferdowsi University of Mashhad. The authors would like to express their gratitude to Mr.saeid for his help during fieldwork.

\section{References}

Afshar Harb, A. 1969. A brief history of geological exploration and geology of the Sarakhs area and the Khangiran field. Bulletin of the Iranian Petroleum Institute 37, 86-93. [In Persian]

Afshar-Harb, A. 1979. The stratigraphy, tectonic and petroleum geology of Kopet Dagh region, northeast Iran. Unpublished PhD thesis,Combined, simplified, lithofacies and isopach map of the Kopet Dagh Basin during deposition of lower part of the Sarcheshmeh Formation (modified from Afshar-Harb, 1979, 1994).Kopet Dagh Basin, Iran 515 Petroleum Geology Section, Royal School of Mines, Imperial College, London, 316 pp.

Afshar-Harb, A. 1982. Geological map of Sarakhs. 1:250 000 (one sheet). Exploration and Production, National Iranian Oil Company (NIOC), Tehran.

Berberian, M. \& King, G. G. P. 1981. Towards a paleogeography and tectonic evolution of
Iran. Canadian Journal of Earth Sciences 18, 210-265.

Hart,M.B., The recognition of Mid-cretaceous sea level changes by means of foraminifera. Cretaceous Research, I, 289-297. (1980a).

Hart,M. B.. A water depth model for the evolution of the planktonic foraminifera. Nature, 286,252-254. (1980b).

Keller, G., The Cretaceous-Tertiary Mass extinction in planktonic foraminifera:Biotic constrains for catastrophe theories, in: Macleod,N., \& G.Keller,Cretaceous-Tertiary mass extions:Biotic \& environmental changes, p.49-83, (1999)

Mohajer, G. 1976. The role of hydrocarbon migration in the formation of Khangiran gas field and its significance in the exploration of the Kopet Dagh Region. The Second Iranian Geological Symposium, pp. 243-262 (Iranian Petroleum Institute, Tehran). [In Persian]

Shafiee Ardestani M, Ghasemi-Nejad E, Vaziri Mogaddam H, 2008. Palaeobathymetry of the Abderaz Formation at type section using planktonic and benthic foraminifera.Journal of Sience University of Tehran. Vol. 34, No.4, Winter 2008. [In Persian]

Wonders, A. A. Middle \& late Cretaceous planktonic Foraminifera of the western Mediterranean area. Utrecht Micropaleontology Bulletin, 24, 1-158, (1980). 


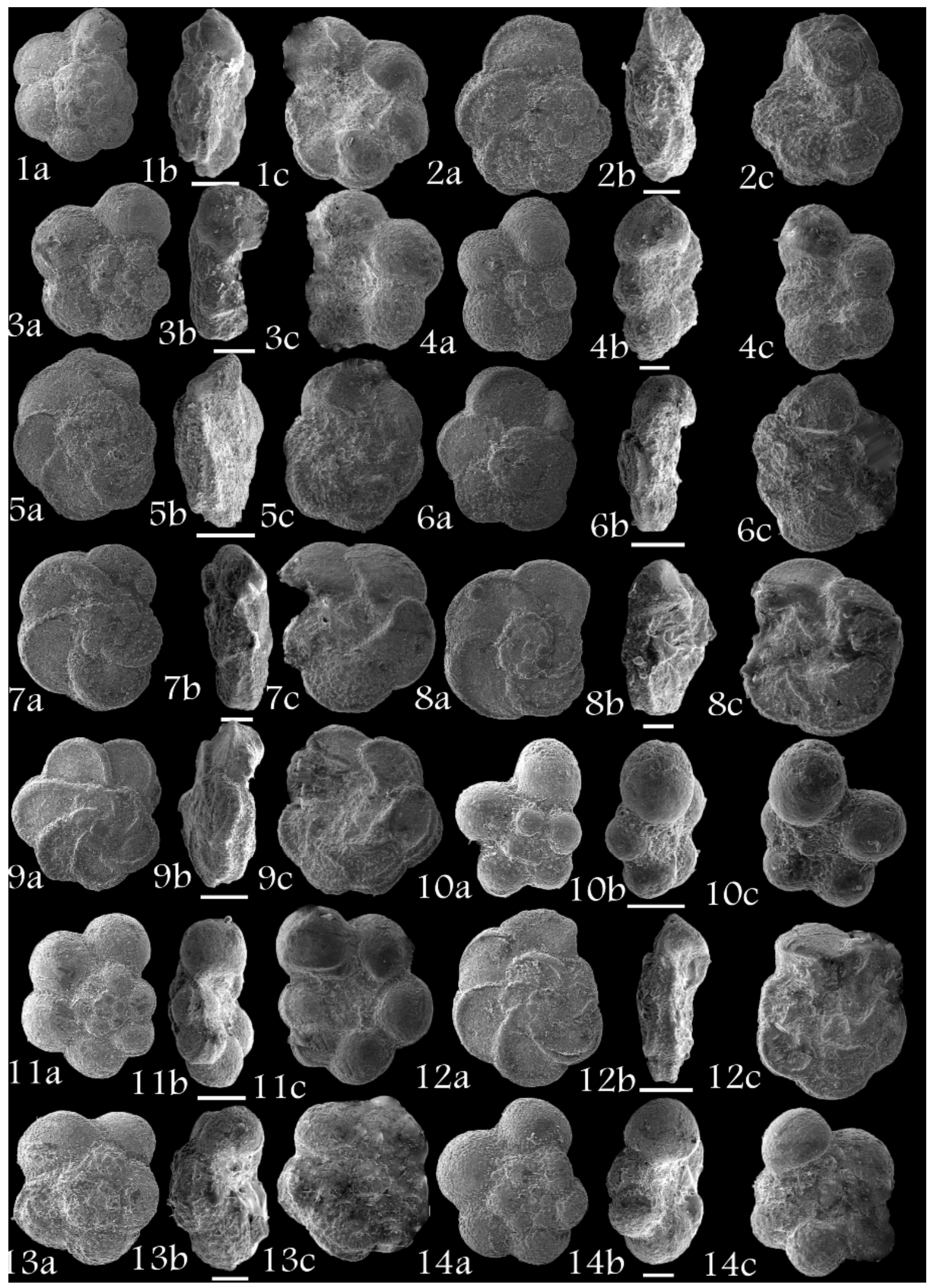

Plate1:1-Marginotruncana marginata, Sample41. 2-Dicarinella imbericata, Sample11. 3, 4-Whiteinella aprica, Sample3. 5, 6, 7Dicarinella imbericata, Sample12, 22, 11. 8-Marginotruncana sinuosa, Sample10. 9-Marginotruncana coronata, Sample6. 10Hedbergella flandrini, Sample23. 11-Praeglobotruncana ef delrioensis, Sample1. 12-Marginotruncana renzi, Sample7. 13-Dicarinella hagni, Sample22. 14-Whiteinella aprica, Sample4. Scale bar represents100 $\mu$ m except for Samples1, 6, 9, 11, 12 which represents $200 \mu \mathrm{m}$. 